\title{
An Exploration on the Development of the Supply Chain Finance of the Banks Based on E-commerce Platform Zhen-qiong WANG
}

\author{
Manufacturing Industry Development Research Center on Wuhan City Circle, \\ Jianghan University, Wuhan, Hubei, 430056
}

Keywords: E-commerce, SMEs, Financing, Supply chain finance of the banks.

\begin{abstract}
Supply chain finance is an innovative financing model for small and medium-sized enterprises (SMEs). The rapid development of the e-commerce promotes the development of supply chain finance from online to offline. This article discusses the prospect of supply chain finance via the e-commerce platform
\end{abstract}

\section{Introduction}

In recent years, some banks have made some financial innovation for SMEs, and the supply chain finance is undergoing a rapid development. The development of supply chain finance promotes the cooperation between the commercial banks and the logistics enterprises, which jointly serve the enterprises located on the supply chains and effectively solve the financing problems of the SMEs on the supply chain.

With the rapid development of Internet economy, e-commerce enterprises cooperate with the financial institutions in launching the Internet financing service platform as the third party to jointly provide online financial services for SMEs. Internet financing is quickly becoming a new financing channel for SMEs.

The supply chain finance of bank utilizes the whole supply chain to make the credibility analysis of SMEs, which is effective to overcome the difficulties in SMEs' financing. The development of the e-commerce platform helps to solve the problem of information asymmetry of SMEs to further promote the stability of the supply chain and to improve the efficiency of the supply chain finance. This article discusses the prospect of supply chain finance via the e-commerce platform.

\section{Firstly, the Supply Chain Finance Is the New Financing Channel for SMEs \\ Traditional Finance Mode Cannot Meet Enormous Funding Demands in SMES}

Due to the limitations of various reasons, bank credit is still the main financing channel for SMEs, but the credit funds that the financial institutions provide for SMEs are very limited, as shown in Figure 1. In recent years, the loan balance in SMEs in China accounts for less than $40 \%$ of that in national financial institutions. Although SMEs account for over $99 \%$ of total enterprises in China, they create nearly $60 \%$ of GDP, and offer $80 \%$ of the jobs. The credit support obtained by SMEs is seriously not in proportion to the contribution they have made. Figure 2 also demonstrates that the traditional credit mode is far from satisfying the credit loan demands of SMEs. 


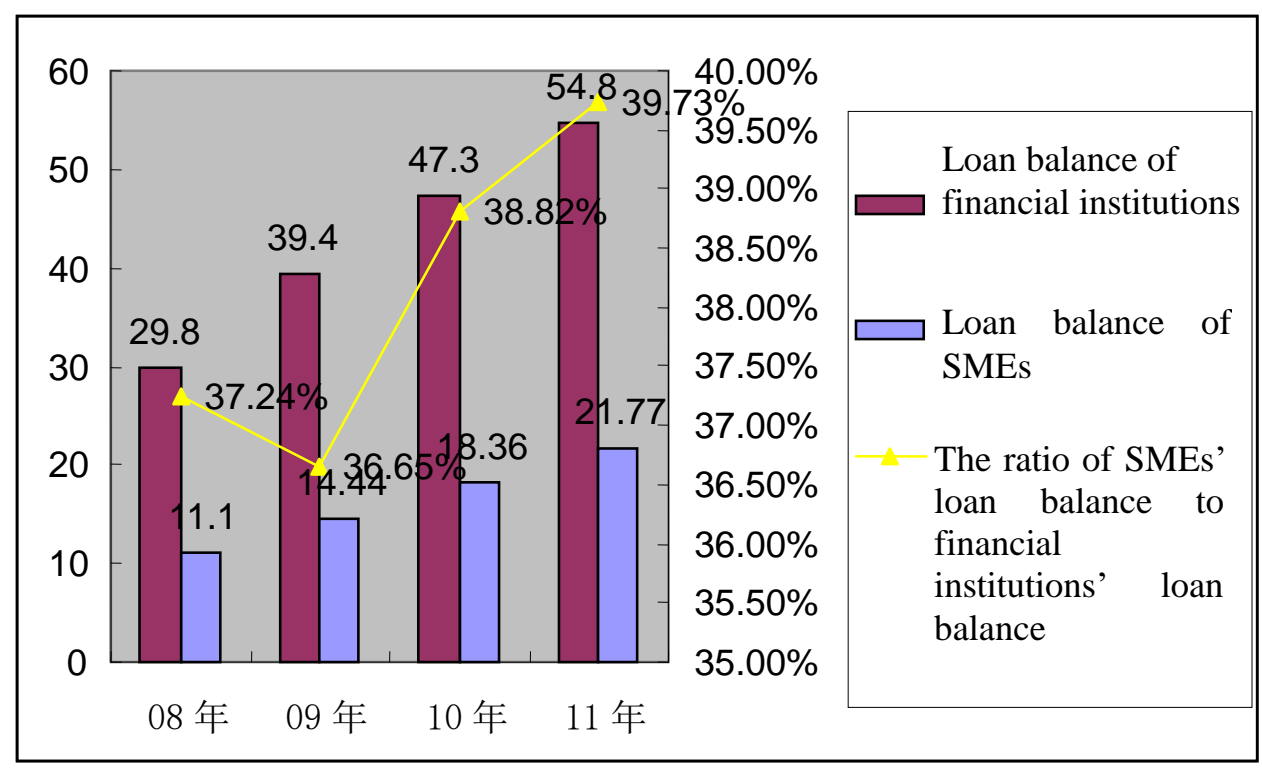

Figure 1 The ratio of Chinese SMEs' loan balance to financial institutions' loan balance in 2008-2011 (unit: trillion yuan,\%) [1]

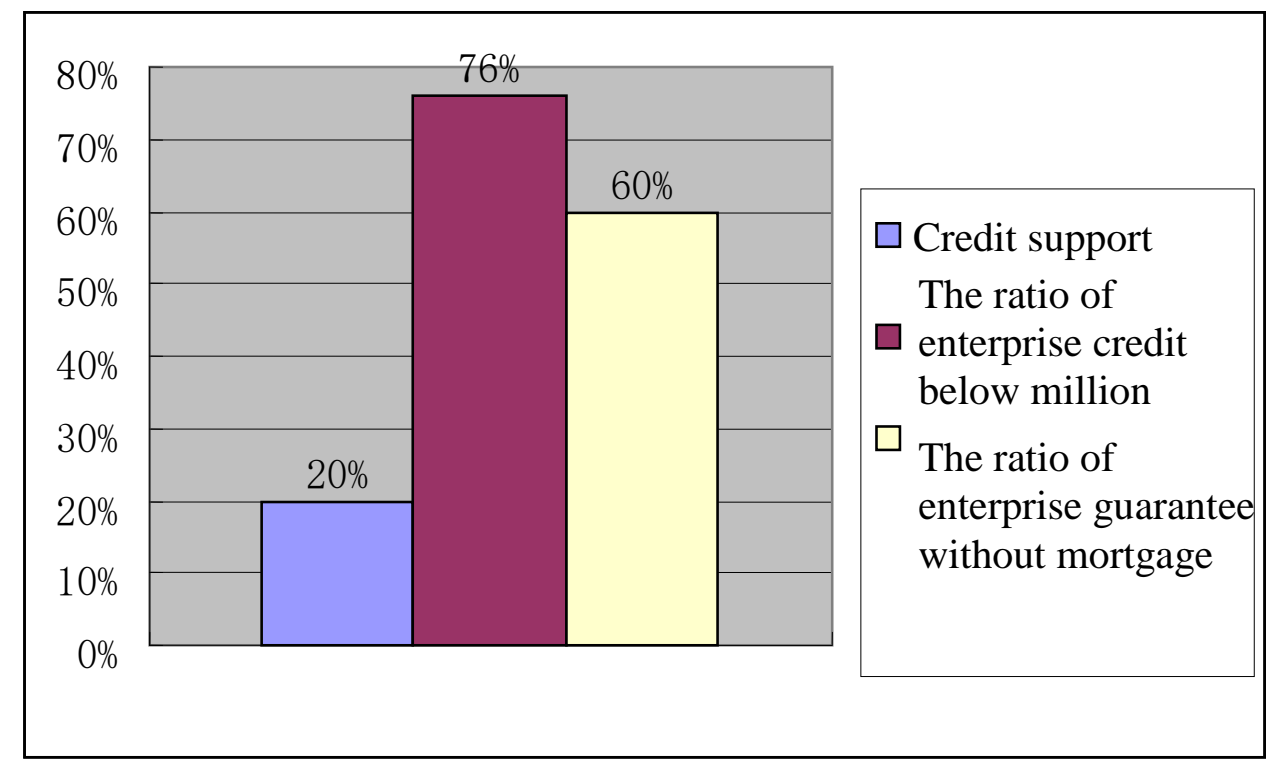

Figure 2 Data map of SMEs (data source: the website of CBRC) [2]

Although, Commercial banks respond to the central government's call to increase credit support for SMEs, SMEs loans accounted for the proportion of the national financial institutions loan increased from $22 \%$ in $2012,23.17 \%$ in 2013 to $23.22 \%$ in 2014. SMEs still facing financing difficulty.

On the one hand, the traditional credit system of commercial banks is strict on the availability of financing for SMEs. On the other hand, the disadvantaged position of SMEs on the supply chain aggravates SMEs' plight with respect to capital turnover. The imbalance of the strength has influenced the smooth flow of funds between the upstream and downstream enterprises on the supply chain [3]. In private enterprises which are mainly SMEs, more than $80 \%$ of them have the problem of insufficient funds and $20 \%$ of them have severe lack of funds. 


\section{Supply Chain Finance Has Opened a New Financing Channel for SMEs}

It has been proved that the difficulty of banks' supervision of current flow can be solved, the current assets such as the inventories of SMEs be vitalized and the demands for chattel financing of SMEs be satisfied through the following mode: the commercial banks cooperate with the third-party logistics enterprises; the banks establish the principal-agent relationship with the logistics enterprises, and the logistics enterprises undertake the supervisory responsibility.

In the activities related to the supply chain finance, the banks make use of the good credit of the core enterprises in the supply chain and enlarge the credit output to promote the overall credit standing of the whole supply chain, improve the information asymmetry of both lenders and borrowers, control the loan risks of low-level credit enterprises with efficiency, curb the risk of the supply chain finance, enhance the material flow and fund flow on the supply chain between the upstream and downstream enterprises, achieve a win-win situation and greatly improve the acquisition of the credit loans for SMEs [4].

\section{E-commerce Environment Has an Effect on the Supply Chain Finance}

\section{The Development of E-commerce has provided Huge Market for the Supply Chain Finance}

In the improving Internet trade environment, the e-commerce is gaining popularity among SMEs because of their convenience, high efficiency and low cost. According to the monitoring data released by China Electronic Commerce Research Center, there were more than 16.5 million SMEs using the third party e-commerce platform by June 2012. The number of the users is expected to reach 18.2 million in 2013 (Table 1). At present, nearly $90 \%$ of the SMEs have the access to the Internet. The e-commerce will maintain the trend of continual growth.

Table 1 Number of SMEs using the third party e-commerce platform in 2008-2013

\begin{tabular}{|c|c|}
\hline Year & Number of users (ten thousand) \\
\hline 2008 & 920 \\
\hline 2009 & 1250 \\
\hline 2010 & 1400 \\
\hline 2011 & 1600 \\
\hline $2012 \mathrm{e}$ & 1730 \\
\hline $2013 \mathrm{e}$ & 1820 \\
\hline
\end{tabular}

Reference material: The Monitoring Report on the China E-commerce Market Data in the First Half of 2012 by China Electronic Commerce Research Center (e sands for estimate).

According to the data provided by the www.youby.com: $30 \%$ of SMEs consider that the enterprises have achieved outstanding competitive edge after the use of e-commerce, and $53 \%$ of the enterprises believe that there is some improvement.

The development and utilization of e-commerce in SMEs makes the cooperation possible between the e-commerce enterprises and the banks, which provides financing for SMEs. The financing of SMEs has the characteristics of short, frequent and rapid, and it needs the batch operation to save the cost. These are exactly the inherent advantages of the e-commerce platform. In recent years, the e-commerce enterprises represented by Alibaba, Network Sheng Bao, and Dun Huang Network cooperate with the banks to launch the third-party Internet financing service platform to provide online financing services for the SMEs in China. This has gradually become a new 
financing channel. As a beneficial attempt, Internet financing like Alibaba developing the supply chain loan in cooperation with China Construction Bank opens a new horizon for the development of supply chain finance.

It is estimated that by the year of 2015 the consumers of e-commerce platform in China will increase from 150 million in 2009 to 500 million; the amount of retail transaction on e-commerce platform will increase from 263 billion in 2009 to 2 trillion, and the proportion of the retail sales of social consumer goods will increase from $2.1 \%$ in 2009 to $7 \%$. At that time, China will have the largest e-commerce service system in the world and the world's first application scale of e-commerce [5]. That means a huge development opportunity for supply chain finance.

\section{The E-commerce Platform Provides the Key Data for the Supply Chain Finance.}

The commercial banks play the leading role in the development of supply chain finance in China. Currently, some e-commerce platforms also join in the competition of the supply chain finance, as the two main parties. One is the supply chain finance of the commercial banks, where the banks are the dominators, and the other is the supply chain finance of entities where the e-commerce entities such as Alibaba, Jing Dong Mall and Su Ning are the representatives [6].

The main problem facing the supply chain finance of bank is the collection and screening of data about SME, which needs the support of the informatized and platform-based credit system. The problems above can be solved by the e-commerce platform. The e-commerce enterprises can fully master the logistics information and trade information of the upstream and downstream enterprises, the shipping and receiving records and other transaction data over the years. By making a good use of them, they can establish an independent credit assessment system for the enterprises, so as to provide the key data about the financing risk control for banks.

So the banks ally with the e-commerce enterprises in the supply chain finance business in launching the business of supply chain finance online. This is not only the expansion of the supply chain finance from offline to online, but also greatly cuts down the cost of SMEs in banking service and promotes the further development of the supply chain finance.

\section{The E-commerce Platform Can Help the Banks Control the Financing Risks.}

There are many credit records about the enterprises on the e-commerce platform. The banks can transform the e-commerce credit into the financing credit, and control the risks of every link of the loaning based on the e-commerce platform. In case there is a breach of contract, overdue, or malicious deadbeat, the relevant information about the enterprises of default will be disclosed without delay on the e-commerce platform. The enterprises with bad credit are exposed to light, which hugely enhances the cost of default, and the default of the enterprises will be effectively curbed.

\section{Conclusion}

Under the e-commerce, supply chain finance offers an promising prospect for SMEs financing. Banks cooperating with the e-commerce enterprises to develop the supply chain finance is not only the demand of further innovation, but also the trend of e-commerce development. This model can help achieve the win-win situation. However, this requires the active participation, close cooperation, the establishment of risk-sharing and interest sharing mechanism, and also the innovation in legal regulation and supervision. 


\section{References}

[1] Liu Jiwei Supply Chain Finance: Make SMEs financing easier,

[2] Yi Bang power network with the full disclosure of supply chain finance: 6 large e-commerce enterprises gathered for microfinance, http://www.ebrun.com/20130116/65815.shtml 09:14:56, 2013-01-16

[3] Zhenqiong Wang, Research on Innovation Development and Risk Prevention of Logistics Financial Business of Commercial Banks in Wuhan City Circle [J], Proceedings of The Tenth International Conference on Innovation and Management, December, 2013

[4] Dong Shaoguang A few opinions on the supporting role of supply chain finance in the development of SMEs, http://finance.sina.com.cn/roll/20100804/00043407393.shtml, August 04, 2010.R.J. Ong, J.T. Dawley and P.G. Clem: submitted to Journal of Materials Research (2003)

[5] Proposals on the promotion of e-commerce development and on the solution to the difficulty of SMEs financing, http://finance.jrj.com.cn/2011/03/0906449395839.shtml 06:44, March 09, 2011.

[6] How banks and e-commerce enterprises control the supply chain finance? http://www.chinairn.com/print/3155304.html. September 28, 2013. 